\title{
Hot topic: Definition and implementation of a breeding value for feed efficiency in dairy cows
}

\author{
J. E. Pryce, ${ }^{*} \dagger^{1}$ O. Gonzalez-Recio, ${ }^{\star}$ G. Nieuwhof, ${ }^{\star} \ddagger$ W. J. Wales, $\S$ M. P. Coffey,\# B. J. Hayes, ${ }^{*} \dagger$ \\ and M. E. Goddard*II \\ ${ }^{*}$ Department of Economic Development, Jobs, Transport and Resources and Dairy Futures Cooperative Research Centre, Agribio, 5 Ring Road, \\ Bundoora, VIC 3083, Australia \\ †School of Applied Systems Biology, La Trobe University, Bundoora, VIC 3083, Australia \\ $\ddagger$ Australian Dairy Herd Improvement Scheme, 22 William Street, Melbourne, VIC 3000, Australia \\ $\S$ Department of Economic Development, Jobs, Transport and Resources, Ellinbank, VIC 3820, Australia \\ \#SRUC, Easter Bush Campus, Midlothian EH25 9RG, United Kingdom \\ IIFaculty of Veterinary and Agricultural Sciences, The University of Melbourne, Parkville VIC 3010, Australia
}

\section{ABSTRACT}

A new breeding value that combines the amount of feed saved through improved metabolic efficiency with predicted maintenance requirements is described. The breeding value includes a genomic component for residual feed intake (RFI) combined with maintenance requirements calculated from either a genomic or pedigree estimated breeding value (EBV) for body weight (BW) predicted using conformation traits. Residual feed intake is only available for genotyped Holsteins; however, BW is available for all breeds. The RFI component of the "feed saved" EBV has 2 parts: Australian calf RFI and Australian lactating cow RFI. Genomic breeding values for RFI were estimated from a reference population of 2,036 individuals in a multi-trait analysis including Australian calf RFI $(\mathrm{n}=843)$, Australian lactating cow RFI $(\mathrm{n}=234)$, and UK and Dutch lactating cow RFI $(\mathrm{n}=958)$. In all cases, the RFI phenotypes were deviations from a mean of 0 , calculated by correcting dry matter intake for BW, growth, and milk yield (in the case of lactating cows). Single nucleotide polymorphism effects were calculated from the output of genomic BLUP and used to predict breeding values of 4,106 Holstein sires that were genotyped but did not have RFI phenotypes themselves. These bulls already had BW breeding values calculated from type traits, from which maintenance requirements in kilograms of feed per year were inferred. Finally, RFI and the feed required for maintenance (through $\mathrm{BW}$ ) were used to calculate a feed saved breeding value and expressed as the predicted amount of feed saved per year. Animals that were 1 standard deviation above the mean were

Received March 24, 2015.

Accepted July 2, 2015.

${ }^{1}$ Corresponding author: jennie.pryce@ecodev.vic.gov.au predicted to eat $66 \mathrm{~kg}$ dry matter less per year at the same level of milk production. In a data set of genotyped Holstein sires, the mean reliability of the feed saved breeding value was 0.37 . For Holsteins that are not genotyped and for breeds other than Holsteins, feed saved is calculated using BW only. From April 2015, feed saved has been included as part of the Australian national selection index, the Balanced Performance Index (BPI). Selection on the BPI is expected to lead to modest gains in feed efficiency.

Key words: feed efficiency, residual feed intake, body weight

\section{INTRODUCTION}

It is widely recognized that selecting for feed efficiency in dairy cattle is highly desirable, as feed costs comprise a large proportion of variable costs associated with dairy production (Shalloo et al., 2004; Ho et al., 2013). However, there has been little success in developing breeding values to select for this trait in dairy cattle breeding (Berry and Crowley, 2013).

The quest to include feed efficiency as part of dairy breeding objectives started in the 1990s, with research at organizations that were able to collect individual feed intake records (Van Arendonk et al., 1991; Nieuwhof et al., 1992; Veerkamp et al., 1994; Veerkamp, 1998). Most of these studies focused on feed efficiency traits calculated using individual feed intake records measured on lactating cows, with the exception of Nieuwhof et al. (1992), who showed that lactating cow feed efficiency was genetically correlated with measurements made in young AI bulls and growing dairy heifers. It was, and still is, expensive to collect data on feed intake and, without sufficient data, a breeding value could not be implemented at that time.

An alternative was to select for improvements in feed efficiency without using real data on feed intake, 
by approximating feed requirements for maintenance based on measurements of BW (Visscher et al., 1994). If appropriately weighted in a selection index that also includes production, controlling maintenance costs through selection will improve gross efficiency; that is, more product is produced per unit of maintenance. In fact, several national selection indices include BW as a breeding objective, predicted using either linear type traits (VanRaden, 2004; VanRaden et al., 2007; Pryce et al., 2014a) or visual estimates of BW, which is the case in New Zealand (Peter Amer, AbacusBio, Dunedin, New Zealand; personal communication). One of the limitations with this approach is that true variation in feed efficiency remains uncaptured. In fact, the correlation between true feed efficiency and predicted feed efficiency (derived from BW and production) was estimated to be 0.84 (Gibson, 1986), implying that there is additional variation in feed efficiency that could be exploited if measurements or predictions of feed intake could be made. One way of capturing the remaining variation in feed efficiency is by selecting for residual feed intake (RFI; Connor, 2015), which is defined as the difference between actual and predicted DMI (Berry and Crowley, 2013; Connor, 2015). In fact, there has been a resurgence of interest in RFI in recent years because of its suitability for genomic selection. Genomic predictions for RFI can be developed in small, well-recorded reference populations that have genotypes and phenotypes, and the prediction equation can then be applied to genotyped animals without phenotypes (Calus et al., 2013; Gonzalez-Recio et al., 2014a). Although genomic selection is an obvious route to enabling breeding values to be estimated for RFI (Pryce et al., 2014a; Tempelman et al., 2015), the size of the reference population and its relationship to the predicted population are limiting factors. For a trait with a heritability of 0.2 , typical of RFI (Connor, 2015), more than 30,000 individuals are required for the reference population to achieve reliabilities of greater than 50\% (Calus et al., 2013; Gonzalez-Recio et al., 2014a). However, even assuming fairly modest reliabilities (18\% in Australian cows, derived from 958 cows from the Netherlands and UK and 843 growing calves; Pryce et al., 2014b), RFI contributes about 3\% per year of the genetic gain for extra profit in Australia (Gonzalez-Recio et al., 2014b).

One of the challenges with traits such as RFI, where negative values are favorable, is making the description of the breeding value clear, so that incorrect interpretation of breeding value estimates is minimized. The lack of clear definition was suggested as one of the reasons for the low uptake of RFI breeding values in the beef industry (Wulfhorst et al., 2010). It is important for un- derstanding acceptance and encouraging wide adoption to carefully consider how to define and subsequently calculate the breeding value.

One solution could be to combine RFI with mature live weight estimated using EBV for predicting maintenance costs, so that feed requirements are quantified in a single breeding value. Here we propose a breeding value, called "feed saved," that can be incorporated into the Australian national selection index, to select for overall economic merit, or alternatively the breeding value can be used independently. For example, where 2 individuals have similar breeding values for milk production traits, the one that requires less feed (for maintenance predicted for BW and RFI combined) will be more efficient and save more feed.

The aims of this paper were (1) to define the expression of a trait (feed saved) that can be used as a breeding value in a way that combines energy requirements for maintenance based on predictions of mature live weight with RFI evaluated in growing calves and lactating cows; and (2) to describe how breeding values could be calculated and implemented for this new trait.

\section{MATERIALS AND METHODS}

\section{Definition of the Trait}

Most classical measures of feed efficiency, such as the ratio of milk output to feed input have significant limitations because (a) they are strongly correlated with milk yield (Prendiville et al., 2009), which is already under intense selection; (b) selection for a ratio trait can lead to unpredictable outcomes; that is, an increase in the error to total variance; and (c) there is no distinction between the energy used for separate functions (Berry and Crowley, 2013). Therefore, it is desirable to use an alternative measure for breeding purposes. Here, a new "feed saved" breeding value for Australia is described. Specifically, it is the feed saved by selecting for cows that have actual feed intake that is less than predicted for their level of production and lower predicted maintenance requirements. This is achieved through combining RFI with feed required for maintenance predicted from BW. Additionally, the RFI trait encompasses both the lactation and the growth phases of life. Including prelactation feed is important because it is estimated that around $25 \%$ of a herd's total DMI is in the prelactating stage (Connor, 2015).

In the dairy industry, many breeding values are expressed such that larger values are more beneficial and while expression of the trait is a cosmetic issue, it is important that the users of the breeding value easily relate to the trait. The sign of the breeding value 
Table 1. Summary of number of calf or cow DMI phenotypes available and country of origin

\begin{tabular}{llcl}
\hline Calf or cow & Country of origin & $\begin{array}{c}\text { No. of cows } \\
\text { or calves }\end{array}$ & Phenotype description \\
\hline Calf & Australia & 843 & $\begin{array}{l}\text { Intakes recorded for } 70 \mathrm{~d} \text { at approximately } 6 \text { mo of age (Pryce et al., } \\
2012)\end{array}$ \\
Lactating cow & Australia & 235 & $\begin{array}{l}\text { Intakes recorded for } 28 \mathrm{~d} \text { in spring or summer, multiparous (mean of } \\
\text { Intake records in first } 100 \mathrm{~d} \text { in first parity (de Haas et al., 2012) }\end{array}$ \\
$\begin{array}{l}\text { Lactating cow } \\
\begin{array}{l}\text { Lactating cow } \\
\text { Total }\end{array}\end{array}$ & $\begin{array}{l}\text { United Kingdom } \\
\text { the Netherlands }\end{array}$ & 359 & $\begin{array}{l}\text { Intake records in first } 100 \mathrm{~d} \text { in first parity (de Haas et al., 2012) } \\
\end{array}$ \\
\hline
\end{tabular}

is therefore reversed, so that high breeding values are interpreted as leading to a larger amount of feed that is saved (i.e., 'better') and confers an improvement.

\section{Calculation of a Breeding Value for Feed Efficiency}

The process to calculate genomic breeding values (GEBV) for feed saved includes (1) calculating phenotypes for RFI for animals included in the reference population; (2) calculating direct genomic values (DGV) for RFI in growth and lactation stages of life; and (3) calculating feed saved GEBV by combining BW EBV with RFI DGV.

The reference population used for genomic prediction of RFI was similar to the population used by de Haas et al. (2012) and Pryce et al. (2014b), except additional Australian lactating cows were included and the phenotype was RFI instead of DMI. In total, 2,036 animals had feed intake data (used to calculate RFI); a breakdown by data set is presented in Table 1 .

\section{Calculating Phenotypes for RFI}

Holstein Calves from Australia. For full details of management of animals, the diets that were fed, and collection of DMI and other data, please refer to Williams et al. (2011). Trait deviations for RFI in growing calves (RFIcalf) were calculated from means of DMI $\left(\mathbf{y}_{D M I_{h}}\right)$ measured over a 6- to 7 -wk period in growing Holstein calves of around 6 mo of age, calculated using the method described by Williams et al. (2011) and Pryce et al. (2012). The linear regression model was as follows:

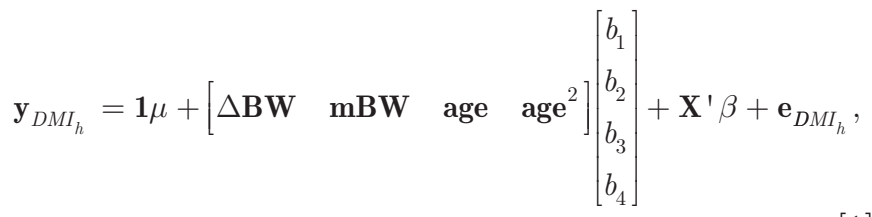

where $\mu$ is the overall mean; $\mathbf{1}$ is a column vector of ones; $b_{1}, b_{2}, b_{3}$, and $b_{4}$ are partial regression coefficients; and $\mathbf{m B W}$ and $\triangle \mathrm{BW}$ are vectors of individual means of BW and change in BW, respectively, measured over the period of the trial, calculated using the method described by Williams et al. (2011) and Pryce et al. (2012). Then, age and $\mathbf{a g e}^{2}$ were linear and quadratic covariates for the age of the calf at the beginning of the experiment, and $\beta$ were systematic environmental effects (experiment, in this case) corresponding to the incidence matrix $\mathbf{X}$. Finally, the residual term $\mathbf{e}_{D M I_{h}}$ was equivalent to RFIcalf.

Holstein Cows from Australia. For full details of management of animals, the diets that were fed, and collection of DMI and other data, please refer to Macdonald et al. (2014) and Pryce et al. (2014b). Phenotypes for RFI in Australian lactating cows (RFIcow) were calculated using a slightly modified version of the model described by Pryce et al. (2014b), where milk, fat, and protein yields were replaced with ECM. Energy-corrected milk was used in preference to its component traits (milk, fat, and protein) to reduce the number of effects that were required to be fitted in the regression to calculate RFIcow (and given that volume, fat, and protein are highly correlated):

$$
\mathbf{y}_{D M I_{c}}=\mathbf{1} \mu+\left[\begin{array}{llll}
\mathbf{D I M} & \mathbf{E C M} & \mathbf{B W} & \Delta \mathbf{B W}
\end{array}\right]\left[\begin{array}{l}
b_{1} \\
b_{2} \\
b_{3} \\
b_{4}
\end{array}\right]+\mathbf{X}^{\prime} \beta+\mathbf{e}_{D M I_{c}}
$$

where $\mathbf{y}_{D M I_{c}}$ is the average DMI over the 28-d experimental period, $\mu$ is the overall mean, $\mathbf{1}$ is a column vector of ones, $b_{1}, b_{2}, b_{3}$, and $b_{4}$ are partial regression coefficients, corresponding to DIM, ECM, BW, and $\Delta \mathrm{BW}$, and which are vectors of individual records for DIM at the beginning of the trial, ECM, mean BW, and $\mathrm{BW}$ change during the trial period, respectively. Then, $\beta$ were systematic environmental effects of trial 
(levels $=1-4)$ and parity (levels $=1-6+)$, with corresponding incidence matrix $(\mathbf{X})$. Finally, the residual term $\mathbf{e}_{D M I_{c}}$ became the vector of phenotypic records for RFI in cows (RFIcow). If more than one lactation record was available for a given animal, the respective RFIcow records were averaged.

Energy-corrected milk $(\mathrm{kg} / \mathrm{d})$, defined as kilograms of milk of standardized composition, was calculated using average daily yields for milk, fat, and protein over the 28-d experimental period (Visscher et al., 1994):

$$
\begin{gathered}
\mathrm{ECM}=0.1 \times \text { milk }(\mathrm{kg} / \mathrm{d})+5.2 \times \text { fat }(\mathrm{kg} / \mathrm{d}) \\
+2.6 \times \operatorname{protein}(\mathrm{kg} / \mathrm{d}),
\end{gathered}
$$

where each coefficient represents the kilograms of DM feed at $11.9 \mathrm{MJ} / \mathrm{kg}$ of DM required to produce $1 \mathrm{~kg}$ of milk, fat, and protein.

European Holstein Cows. The UK and Dutch data reported by de Haas et al. (2012) were used to calculate RFI in overseas cows (RFIov) and included DMI phenotypes $\left(\mathbf{y}_{D M I_{o v}}\right)$ precorrected for fixed effects (see de Haas et al., 2012 for further details) and available for 359 UK cows and 599 cows from the Netherlands (NLD). To calculate RFI, GEBV for milk production traits and BW were included in the regression equation, as phenotypes for overseas animals were not available. The advantage of this strategy is that as the reference population increases in size through the addition of DMI phenotypes from overseas, RFIov can be calculated by regressing DMI on GEBV for ECM and BW. If RFI were calculated conventionally, we would also need to gain access to other phenotypic records, such as BW and milk production. The Australian Dairy Herd Improvement Scheme (ADHIS, Melbourne, Australia) official genomic prediction equations were used to calculate GEBV for BW $\left(\mathbf{B W}_{\text {gebv }}\right)$, milk, fat and protein yields. Then, equation [3] was applied to genomic breeding values for milk, fat, and protein yields to calculate ECM GEBV $\left(\mathbf{E C M}_{g e b v}\right)$. The following model [4] was then applied:

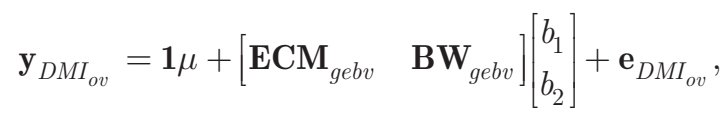

where $b_{1}$ and $b_{2}$ are regression coefficients for $\mathbf{E} \mathbf{C M}_{\text {gebv }}$ and $\mathbf{B} \mathbf{W}_{g e b v}$, respectively, and $\mathbf{e}_{D M I_{o v}}$ was used as the cow RFI phenotype for overseas cows (RFIov).

\section{Genotypes}

In total, 28,621 SNP were in common between Australian and overseas data sets and these were selected as genotypes for animals included in this study. Incidentally, the genotypes were very similar to those used in the study of de Haas et al. (2012). Briefly, the Australian calves were genotyped using the Illumina High Density Bovine SNP chip (Illumina, San Diego, CA; www.illumina.com/agriculture). After quality control procedures applied by Pryce et al. (2012), 624,930 SNP remained. The Australian, UK, and Dutch cows were genotyped using the Bovine SNP50 Beadchip (Illumina Inc.). The Australian lactating cow genotypes were provided by the Australian Dairy Herd Improvement Scheme and were processed as part of their routine procedures for genomic selection. A total of 43,971 SNP passed the quality control steps described by Erbe et al. (2012). There were 37,069 SNP that passed quality control procedures applied to the SNP50 genotypes of UK and Dutch cows (de Haas et al., 2012). The next step was to combine genotypes from the 3 sources where the SNP map positions were the same. After this, an editing procedure that excluded SNP on the X chromosome was applied, as de Haas et al. (2012) reported large differences in allele frequencies on this chromosome between Australian and European populations. Additionally, SNP were also deleted when differences were observed between genotypes of 40 bulls that were genotyped by both the Australian and European collaborators following de Haas et al. (2012). Finally, the number of SNP in common was 28,621 .

\section{Calculation of RFI GEBV}

A multi-trait analysis (RFIcalf, RFIcow, RFIov) was used to calculate genetic correlations between RFI traits and to generate GEBV for RFI in Australian calves and cows and in overseas cows. This model allows the correlations between traits to be estimated.

The model used was

$$
\mathbf{y}_{\mathrm{T}}=\mathbf{X}_{\mathrm{T}} \mathbf{b}_{\mathrm{T}}+\mathbf{Z}_{\mathrm{T}} \mathbf{g}_{\mathrm{T}}+\mathbf{e}_{\mathrm{T}},
$$

where $\mathbf{y}_{\mathbf{T}}$ is the $3 \times n$ matrix of observations on all traits, $\mathbf{X}_{\mathbf{T}}$ is the incidence matrix for fixed effects, $\mathbf{b}_{\mathbf{T}}$ is the matrix of fixed effect solutions (in this case, the mean for each trait and country of origin), $\mathbf{Z}_{\mathrm{T}}$ is an incidence matrix mapping records to animals, $\mathbf{g}_{\mathrm{T}}$ comprises genomic breeding values for all traits for animals with genotypes, distributed as $N(0, \mathbf{G} \otimes \mathbf{K})$, and $\mathbf{e}_{\mathbf{T}}$ is a $3 \times$ $n$ matrix of residual terms; $\mathbf{K}$ is a $3 \times 3$ matrix of additive genetic (co)variances between RFIcalf, RFIcow, and RFIov, and $\mathbf{G}$ is the animal by animal genomic relationship matrix constructed from the genotypes as described by Yang et al. (2010). Then, $\mathrm{V}\left(\mathrm{e}_{\mathrm{T}}\right)=\mathbf{R} \otimes \mathbf{I}$, where $\mathbf{R}$ is a $3 \times 3$ matrix of error (co)variances and $\mathbf{I}$ 
is an $n \times n$ identity matrix. Variance components were estimated with ASREML (Gilmour, 2006).

For every animal with genotypes in G, 3 DGV were produced: RFIcalf DGV, RFIcow DGV, and RFIov DGV. Regression equations that allow both RFIcalf and RFIcow to be computed from SNP markers were calculated by back solving the mixed model equations. The estimation of SNP coefficients is calculated as $\hat{\boldsymbol{\beta}}=\mathbf{H}^{\prime}\left(\mathbf{H H}^{\prime}\right)^{-1} \hat{\mathbf{g}}$, where $\mathbf{H}$ is the $n \times 28,621$ matrix of the genotypes of $n$ animals in the reference set, with genotypes coded as 0,1 , and 2 for aa, Aa, and AA, respectively, and $\hat{\mathrm{g}}$ is the DGV for RFIcalf or RFIcow animals in the reference set.

Then, prediction of either cow or calf RFI DGV for any animal with genotype is $\hat{\mathbf{g}}_{v}=\mathbf{H}_{v} \hat{\boldsymbol{\beta}}$, where $\mathbf{H}_{v}$ is the 0,1 , or 2 genotype coded matrix of animals adjusted for $2(\Sigma p q)$, using the corresponding SNP coefficients (cow or calf RFI). Genomic breeding values were calculated using this regression equation applied to the genotypes of 4,106 Holstein bulls.

As described earlier, one of the aims of this study was to calculate a breeding value that incorporated RFI in growing and lactating cows. Therefore, we combined the DGV for RFIcalf and RFIcow to calculate lifetime RFI ( $\left.\mathbf{R F I}_{\text {life }}\right) ; \mathbf{R F I}_{\text {life }}$ was expressed in kilograms of feed per year over a 6 -yr period and assumes a rearing period of $2 \mathrm{yr}$ and productive, or lactating, period of $4 \mathrm{yr}$, where $4 \mathrm{yr}$ is the rounded-down number of lactations of herd-recording Australian Holstein, Jersey, and crossbred cows. Here, $\mathrm{RFI}_{\text {life }}$ was calculated by multiplying the DGV for RFIcow by days in lactation (days), which was an accepted length of lactation (305 d) and deliberately excluded the 60-d dry period, when feed costs and daily feed intake are considerably lower as cows are moved to cheaper diets. Similarly, RFIcalf was multiplied by days of life before lactation commenced, which was assumed to be $2 \mathrm{yr}$ minus the period from birth to weaning of $30 \mathrm{~d}$ (when the diet is predominantly milk), which is $700 \mathrm{~d}$. Finally, there is a division by 6 (2 yr as a calf $+4 \mathrm{yr}$ as a lactating cow) to annualize to $\mathrm{RFI}_{\text {life }}$ as follows:

$$
R F I_{\text {life }}=\frac{\text { RFIcow } \times 305 \times 4+\text { RFIcalf } \times 700}{6} .
$$

\section{Calculation of Feed Required for Maintenance}

Our definition of the feed saved breeding value is that it combines the feed required for maintenance with residual feed intake. Maintenance requirements (in MJ) are generally considered to be a function of BW (e.g., Visscher et al., 1994). Consequently, BW EBV calcu- lated using existing ADHIS methodology were used for this calculation (see Haile-Mariam et al., 2014, for more details). The marginal amount of feed required to maintain a given EBV of BW was calculated using the cost of increasing BW by 1 unit. In Australia, EBV for BW have a mean of 100 , so the first step was to calculate BW EBV deviations around a mean of 0 . The economic value of $\mathrm{BW}$ was calculated to be $-\mathrm{A} \$ 5.42 / \mathrm{yr}$ (Tim Byrne, AbacusBio, personal communication), where $\mathrm{A} \$$ $=$ Australian dollars This is divided into maintenance costs $-\mathrm{A} \$ 7.34 / \mathrm{yr}\left(\mathrm{EV}_{\mathrm{BW}}\right)$, which was used in our calculations, and cull cow and calf costs of $\mathrm{A} \$ 1.92 / \mathrm{yr}$. The cost of feed in MJ (feedcost) was $\mathrm{A} \$ 0.025 / \mathrm{MJ}$ and the energy content of feed (MJME) was $11.9 \mathrm{MJ} / \mathrm{kg}$ of DM. Using these assumptions the feed required to maintain $1 \mathrm{~kg}$ of extra BW (Feed_BW_kg) can be calculated as follows:

$$
\text { Feed_ } B W_{-} k g(\mathrm{~kg} / \mathrm{yr})=\frac{E V_{B W}\left(E B V_{B W}-100\right)}{\text { feedcost } \times M J M E} .
$$

\section{Feed Saved Breeding Values}

The variable Feed $\_B W \_k g$ is expressed so that a large value represents more feed saved because maintenance costs are lower for lesser-weight cows. Residual feed intake is then subtracted from Feed $\_B W_{-} k g$ so that the feed saved EBV (FS_kg) is kilograms (DM) of feed that is saved:

$$
F S \_k g=F e e d \_B W \_k g-R F I_{l i f e} .
$$

\section{Reliability of Feed Saved Breeding Value}

The reliabilities of EBV for BW are already calculated routinely as part of the genetic evaluation service of the ADHIS. However, reliabilities are also required for RFIcow and RFIcalf for genotyped animals without phenotypes. We achieved this by inverting the coefficient matrix that incorporates animals with and without records in the system of equations. The ratio between residual and genetic variances for RFIcow and RFIcalf were 4 and 1.85, respectively (derived from the variance components, respectively). The reliabilities were derived based on the equations from the univariate analyses (RFIcow and RFIcalf) with different weights on the records from RFIcow (1 or 0.65$)$, RFIcalf $(0.65$ or 1 ), or RFIov (0.70). The weights approximated the genetic correlations between respective traits.

The combined reliability of RFI ( Rel $\left._{\text {RFIlife }}\right)$ was calculated using an approximation of the contribution of RFIcalf and RFIcow to $\mathrm{RFI}_{\text {life, }}$, which was 
Table 2. Phenotypic SD, heritability (diagonal), and genetic correlation estimates for residual feed intake measured in Australian cows (RFIcow), Australian calves (RFIcalf) and UK and Dutch cows (RFIov) above the diagonal estimated using genomic relationships ${ }^{1}$

\begin{tabular}{lcccc}
\hline Item & Phenotypic SD & RFIcow & RFIcalf & RFIov \\
\hline RFIcow & 1.26 & $0.20(0.20)$ & $0.67(0.45)$ & $0.76(0.60)$ \\
RFIcalf & 0.42 & & $0.35(0.08)$ & $0.30(0.22)$ \\
RFIov & 0.97 & & $0.35(0.06)$ \\
\hline
\end{tabular}

${ }^{1}$ Standard errors are presented in parentheses.

$$
\operatorname{Re}_{\text {RFIlife }}=0.25 \times \operatorname{Re}_{\text {RFIcalf }}+0.75 \times \operatorname{Rel}_{\text {RFIcow }} . \quad[9]
$$

Finally, the reliability of the feed saved EBV combines the reliabilities of the RFI GEBV and BW EBV as

$$
R e l=1-\frac{P E V}{\sigma_{F S}^{2}},
$$

where $P E V$ is the prediction error variance calculated as follows:

$$
P E V=\left(1-\operatorname{Re}_{R F I l i f e}^{2}\right) \sigma_{R F I}^{2}+\left(1-\operatorname{Re}_{B W}^{2}\right) \sigma_{B W}^{2} .
$$

No covariance was included between RFI and BW because the estimate of this was small, as RFI is already corrected for BW.

For BW, ADHIS EBV for BW in Holstein bulls with published proofs have a standard deviation of 3.7 $\left(\sigma_{\text {BWABV }}\right)$. Body weight EBV are presented by ADHIS as deviations from a mean of 100 (within breed) and in percentage of the phenotypic mean, where a $1 \%$ increase in live weight is equivalent to $4.8 \mathrm{~kg}$. The energy required to maintain $1 \mathrm{~kg}$ of $\mathrm{BW}$ is $0.1138 \mathrm{MJ}$ of $\mathrm{ME} /$ $\mathrm{kg}$ (Visscher et al., 1994) and therefore the variance of MJ BW is $\left(\sigma_{\mathrm{BWABV}} \times 4.8\right)^{2} \times 0.1138$.

\section{RESULTS}

\section{Genetic Parameters}

The heritability of RFI in Australian cows was 0.20 and heritabilities for growing calves and a combined data set of Dutch and UK cows were both 0.35 (Table
2 ), both of which are in the range of previous studies (Pryce et al., 2014a; Tempelman et al., 2015). The genetic correlation between RFI in growing calves and lactating cows was $0.67( \pm 0.45)$. A larger additive genetic correlation $(0.76 \pm 0.60)$ was estimated between RFIov and RFIcow, whereas a lower genetic correlation $(0.30 \pm 0.22)$ was found between RFI in growing calves and RFI in overseas lactating cows. The standard errors of the estimates were large in general, as expected given the limited data, especially for Australian lactating cows.

\section{Feed Saved Breeding Values for Bulls}

The DGV for RFIcalf and RFIcow had standard deviations of $0.09 \mathrm{~kg} / \mathrm{d}$ and $0.21 \mathrm{~kg} / \mathrm{d}$, respectively (Table 3). The standard deviations of $\mathrm{RFI}_{\text {life }}$, Feed_BW_kg, and $\mathrm{FE} \_\mathrm{kg}$ were $50.5 \mathrm{~kg} / \mathrm{yr}, 47.0 \mathrm{~kg} / \mathrm{yr}$, and $65.6 \mathrm{~kg} /$ yr, respectively (Table 3 ). As expected, calf and cow RFI were not correlated with BW (Figure 1) because RFI has already been corrected for BW. Therefore, the 2 components of the feed saved breeding value can be considered to be independent of one another.

The genetic trend for feed saved is shown in Figure 2 and includes a subset of the genotyped bulls that were born from 1990 onward. It can be seen that from around 2000, there has been an increase in EBV for maintenance requirements and RFI; consequently, the genetic trend for feed saved is unfavorable.

\section{Reliabilities of Feed Saved EBV}

The genetic variance of RFIlife was $42,509 \mathrm{~kg}^{2} / \mathrm{yr}$. This was calculated by combining the daily genetic

Table 3. Mean, SD, and range of EBV for residual feed intake in cows (RFIcow) and calves (RFIcalf), lifetime residual feed intake (RFIlife), the feed required for BW (Feed_BW_kg) and feed saved (FS) for 4,106 genotyped Holstein bulls

\begin{tabular}{lrrrrr}
\hline Item & $\begin{array}{c}\text { RFIcow } \\
(\mathrm{kg} / \mathrm{d})\end{array}$ & $\begin{array}{c}\text { RFIcalf } \\
(\mathrm{kg} / \mathrm{d})\end{array}$ & $\begin{array}{c}\text { RFIlife } \\
(\mathrm{kg} / \mathrm{yr})\end{array}$ & $\begin{array}{c}\text { Feed_BW_kg } \\
(\mathrm{kg} / \mathrm{yr})\end{array}$ & $\begin{array}{c}\text { FS } \\
(\mathrm{kg} / \mathrm{yr})\end{array}$ \\
\hline Mean & 0.07 & 0.02 & 16.7 & -16.9 & -33.6 \\
SD & 0.21 & 0.09 & 50.5 & 47.0 & 65.6 \\
Maximum & -0.75 & 0.43 & 182.0 & 215.1 & 192.5 \\
Minimum & 0.64 & -0.28 & -162.7 & -218.8 & -285.1 \\
\hline
\end{tabular}




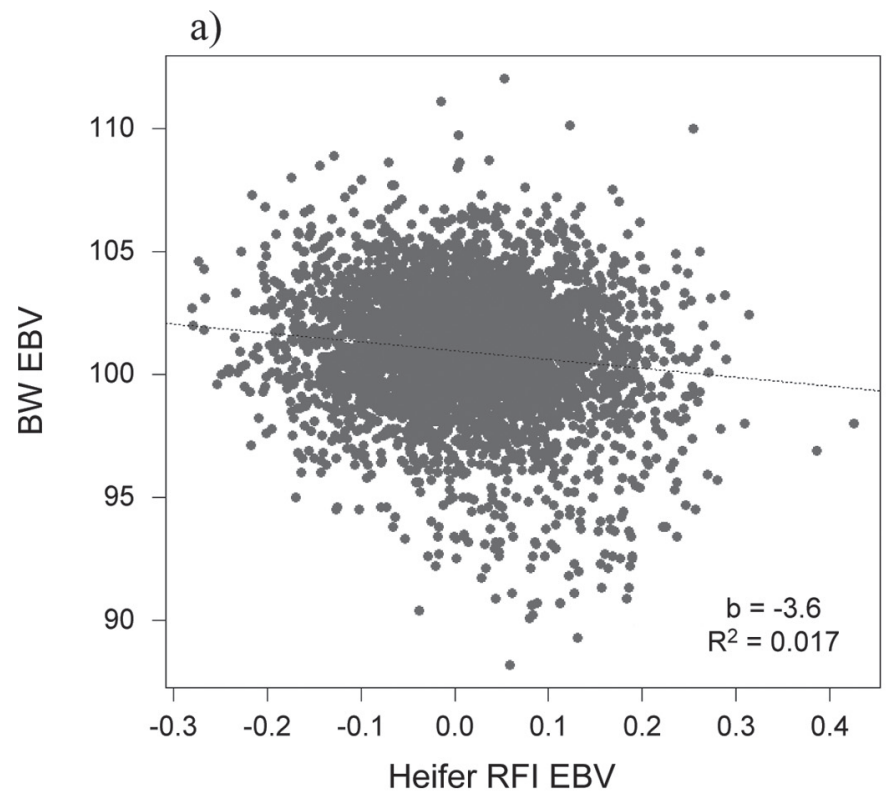

b)

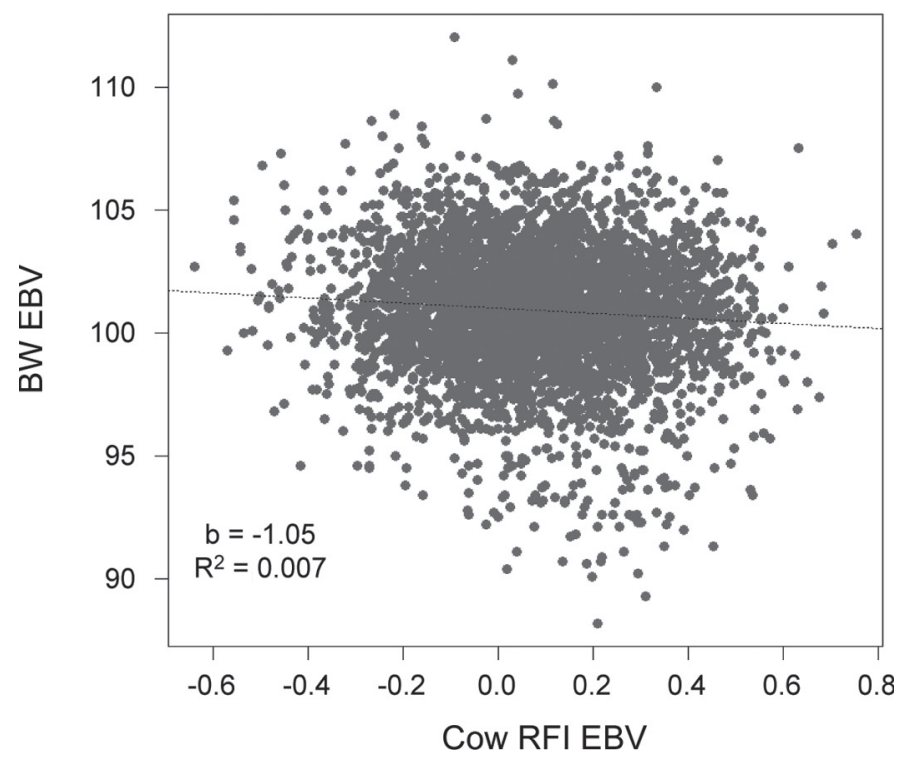

Figure 1. The relationships between EBV of genotyped Holstein bulls (1) for calf residual feed intake (RFI) and BW; and (2) for cow RFI and BW. The slope coefficient (b) and adjusted $\mathrm{R}^{2}$ coefficient calculated using linear regression are shown.

variance of RFIcalf and RFIcow, which was $0.32 \mathrm{~kg}^{2} / \mathrm{d}$ over a 2-yr rearing period and $4 \mathrm{yr}$ of lactation. The variance of $\mathrm{BW}$ in $\mathrm{kg}$ of feed $\mathrm{DM}$ per year was 26,239 $\mathrm{kg}^{2} / \mathrm{yr}$ and the variance of feed saved was RFI $\left(\mathrm{kg}^{2}\right)+$ BW $\left(\mathrm{kg}^{2}\right)$, which was $68,748 \mathrm{~kg}^{2} / \mathrm{yr}$.

The BW reliabilities calculated by ADHIS for 4,106 genotyped Holstein sires had a mean of 0.50 and standard deviation of 0.13 , whereas RFIlife reliabilities had

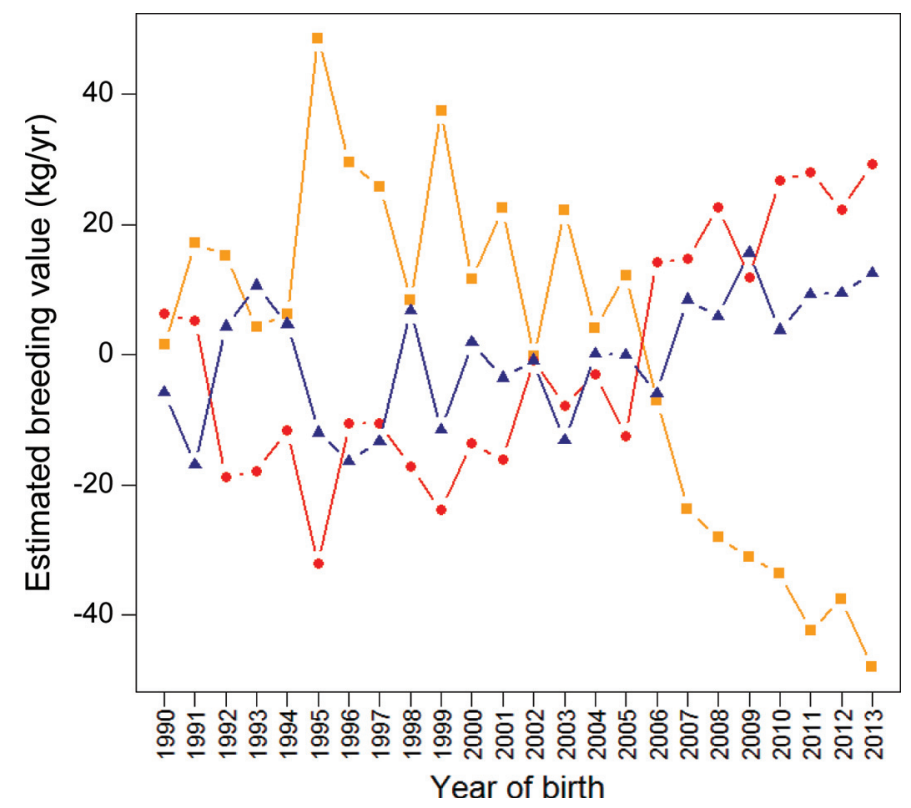

Figure 2. Genetic trend of EBV for bulls born in or after 1990 for residual feed intake (RFI; triangles, blue), feed required for BW (circles, red), and feed saved (squares, orange), all shown in kilograms per year. Color version available online.

a mean of 0.06 and standard deviation of 0.07 . A distribution of the reliability of feed saved is shown in Figure 3 , where the mean was 0.37 and standard deviation was 0.06 , with a range from 0.24 to 0.74 .

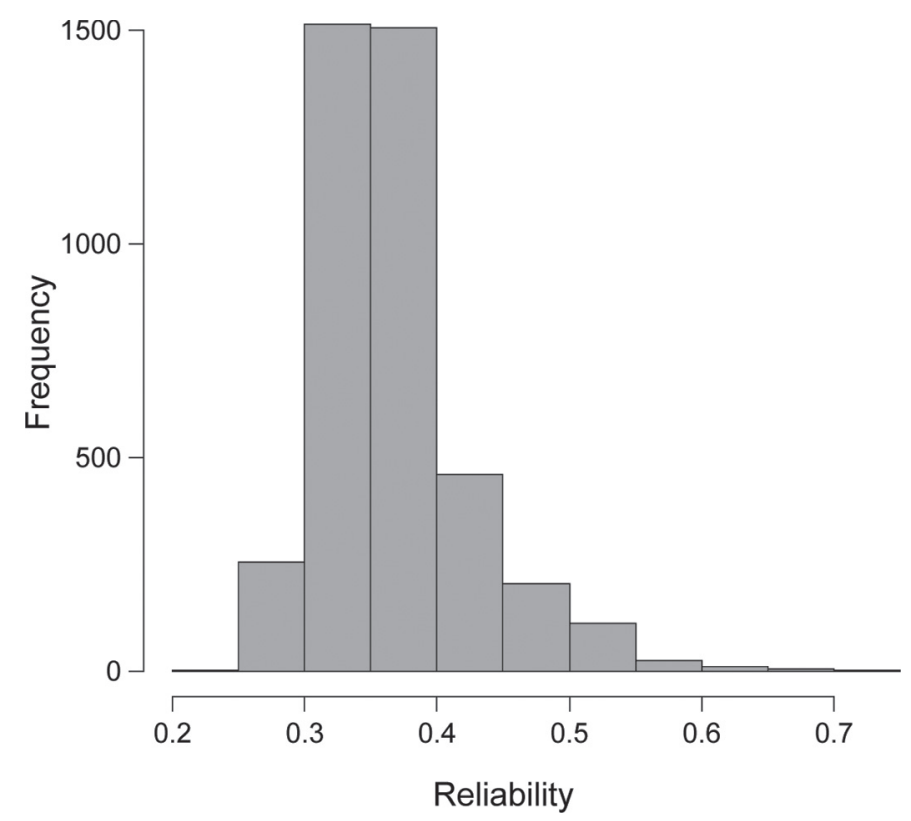

Figure 3. Histogram of the reliability of feed saved in genotyped Holstein bulls. 


\section{DISCUSSION}

We have described the methodology to predict a new "feed saved" breeding value for the Australian dairy industry. It combines RFI in growing calves and lactating cows with feed required for maintenance predicted from BW. Residual feed intake is the difference between actual and predicted feed intake and, although the biological basis is not well understood (Davis et al., 2014), it is thought to capture variation in activity, the efficiency of converting feed into product (Berry and Crowley, 2013), and energy lost as heat (Herd and Arthur, 2009; DiGiacomo et al., 2014). The rationale for combining RFI and feed required for maintenance predicted from $\mathrm{BW}$ is that feed requirements are accounted for in the same breeding value. Selecting for this trait in tandem with other traits of economic importance via a selection index leads to selection for improved feed efficiency.

Others, such as Berry and Crowley (2013), have proposed combining traits related to feed efficiency in a similar way to the feed saved breeding value we have described. The trait they proposed was for beef cattle and called residual intake and gain, which combined residual BW gain with RFI. Veerkamp et al. (2014) suggested selecting for reduced DMI predicted using actual DMI records in addition to selected yield and type traits. In fact, DMI could be considered as including RFI and feed required for major energy sinks such as BW (for maintenance) and milk production. Provided all the traits in an index for overall genetic improvement are appropriately weighted, the net effect should be equivalent to the feed saved trait we are proposing.

The advantage with feed saved is that animals with the same RFI can be distinguished on the basis of their maintenance requirements. Then, all else being equal, larger animals will be penalized for greater maintenance costs. As RFI is corrected for BW, this is an important distinction and the reason why feed saved (integrating RFI and maintenance costs associated with higher BW) is a more desirable trait for implementation compared with RFI.

Tempelman et al. (2015) combined data from research stations in the United States, United Kingdom, and the Netherlands and observed heterogeneous variation in RFI arising from multiple environments from which data were sourced. Therefore, multivariate analyses are preferable when the trait is measured in different environments or life stages (De Haas et al., 2012) as they can treat differences both in trait definitions and genotype by environment interactions appropriately. The genetic correlation between growing calf and lactating cow RFI in our analysis was 0.67 , which is very close to the inferred estimate of 0.6 determined by selecting Australian and New Zealand calves that had extreme high or low RFI in the growth phase and then retesting in their first lactation (Macdonald et al., 2014), and the correlation between RFI in Dutch lactating cows and growing calves was 0.58 (Nieuwhof et al., 1992). The genetic correlation of RFI in Australian and overseas lactating cows was 0.76 , which is higher than the European Union low-input and grazing correlation of DMI estimated at 0.57 (Berry et al., 2014a); however, the data set we used was a subset of that of Berry et al. (2014a), and the trait they used was DMI, whereas we used RFI.

One of the limitations with the trivariate analysis was the large standard errors of the genetic parameter estimates, especially for genetic correlations for Australian lactating cow RFI. As more Australian lactating cow data are accumulated, the standard errors are expected to decrease, which would lead to less reliance on cow data from other countries. Ultimately, it may be possible to replace the trivariate model we used with a bivariate model of Australian growing calves and lactating cows. However, although the data sets for difficult or expensive-to-measure traits are growing, international collaboration is likely to be the short- to medium-term solution to obtain acceptable reliabilities for novel traits that are only collected in females (Pryce et al., 2014a; Egger-Danner et al., 2015). Predictor traits can also improve the accuracy of predicting DMI; for example, Pszczola et al. (2013) showed an increase in accuracy from adding ECM and live weight, whereas Manzanilla Pech et al. (2014) realized greater accuracies from conformation data.

Calculated bull reliabilities for RFI were low $(<0.10)$. In accordance with our earlier study, using a subset of data in the reference population (Pryce et al., 2014b), a considerable amount of error exists in the prediction of RFI using small reference data sets. Weak relationships of some of the bulls to the reference population may also have impaired the accuracy of prediction (Clark et al., 2012). Furthermore, reliabilities estimated by inversion are sensitive to the parameterization of $\mathbf{G}$ and can result in misleading results (Strandén and Christensen, 2011). Therefore, the reliability estimates of RFI should be treated with caution.

By combining the reliability of RFI with BW, the mean reliability of feed saved in bulls was 0.37. Although this is a low reliability trait when compared with other traits (e.g., the mean reliability of BW for the same set of bulls was 0.5), others have shown that the reliability of comparable traits will improve as the size of the reference population increases (Calus et al., 2013; Gonzalez-Recio et al., 2014a). 
The standard deviation of feed from BW was about 1.5 times greater than that of $\mathrm{RFI}_{\text {life, }}$, so the relative contribution of BW to the feed efficiency EBV was considerably larger than the contribution of RFI. Although calculating RFI for only $305 \mathrm{~d}$ of the year was conservative, we assumed that RFI is the same trait across lactations, which may not be the case. For example, the correlation between DMI in early and late lactation is relatively weak (Manzanilla Pech et al., 2014). As feed intake measurements were made on calves at about 6 mo of age, this is also likely to reflect a conservative approach. That is, greater variation in RFI would be expected later in the growing period when DMI is also greater.

In addition to a small number of Australian cow records for RFI, the other limitation with the way we evaluated RFI is accounting for differences in body composition or changes in body composition. Although $\mathrm{BCS}$ is the accepted measure of fat reserves in dairy cattle, it is generally scored on a relatively limited scale, which makes evaluating changes in BCS difficult for a data set of only several hundred cows over a relatively short period. New automated ways of evaluating BCS are being developed (Roche et al., 2009), which could improve the measurement of BCS changes. It could be that variation in RFI is merely detecting differences between animals in body reserves. However, if this were the case, then RFI would be correlated with fertility. In fact, a weak correlation $(\sim 0.1)$ is found between RFI and fertility (Pryce et al., 2014a) that should be monitored. To put this into perspective, correlations of measures of fertility (calving interval, days open, pregnant within a time period, and nonreturn rate) and BCS in a meta-analysis ranged between 0.35 and 0.51 (Berry et al., 2014b), with the signs being switched for some of these correlations for ease of interpretation, illustrating that all are unfavorable. Therefore, if BCS partially explains RFI, there is still variation that captures true differences in feed efficiency. Advancements in accurately quantifying body reserves in dairy cattle will benefit genetic prediction of RFI. For the time being, including feed saved as part of a multi-trait selection index for profit that also includes fertility, as well as traits such as survival and mastitis resistance, should help to guard against undesirable correlated responses in, for example, fertility.

Although the measure of feed efficiency that we have described in this study is not a classical measure of feed efficiency, when it is included in a multi-trait selection index for overall profit, the net result is an improvement in economic efficiency. Gonzalez-Recio et al. (2014b) found that by including RFI in the Australian Profit Ranking index (APR), RFI would continue to increase such that cows would become more inefficient, but at a slower rate than if RFI was removed from the index. We have repeated these calculations and replaced BW and RFI used in the calculations of Gonzalez-Recio et al. (2014b) with feed saved, which is part of the new Australian national selection index, the Balanced Performance Index (BPI), which replaced APR in April 2015. The BPI is expected to result in an improvement in feed efficiency of around $0.5 \mathrm{~kg} / \mathrm{yr}$, which would add around $\mathrm{A} \$ 0.15$ to net profit per cow per year of selection. We also evaluated the correlated response of feed saved through increasing BPI in a large data set of current Holstein sires born since 1990. For every 10-unit increase in BPI (worth approximately A $\$ 10$ ) and approximately the rate of genetic gain achieved in Australian Holsteins, an approximately $0.55-\mathrm{kg}$ improvement in feed saved will be achieved.

Farmers can also select directly on feed saved. If a cow eats approximately $20 \mathrm{~kg}$ of $\mathrm{DM} / \mathrm{d}$ (Macdonald et al., 2014) and a growing calf eats approximately $8 \mathrm{~kg}$ of DM/d (Williams et al., 2011), then both groups eat close to 6 t over a 305-d and 700-d period, respectively. Cows with EBV that are $1 \mathrm{SD}$ above the mean $(+66$ $\mathrm{kg} / \mathrm{yr}$ ) are likely to save around $1 \%$ of annual feed costs. If all the 1.7 million dairy cows in Australia ate 1\% less feed, this would save 103,700 t DM/yr of feed and, by association and assuming that $8 \mathrm{t}$ of $\mathrm{DM} /$ ha of pasture is consumed by cows per year, this would save about 13,000 ha of land, which could then be used for human food production, assuming the land is also suitable for other food sources to be grown.

\section{CONCLUSIONS}

Selection for feed efficiency has historically relied on approximations of feed requirements estimated using BW. However, this is unlikely to capture all the variation in feed efficiency. Through genomic selection, opportunities now exist to extend this to include measures of efficiency derived from actual feed intake data, such as RFI. We have described how a feed efficiency breeding value can be derived by combining RFI and BW. Although the mean reliability of this new trait was comparatively low compared with other traits, we expect that this will improve as the reference population is extended. Ultimately, the best way to select for improvement in this trait is through a multi-trait selection index that includes all traits that contribute to profitability.

\section{ACKNOWLEDGMENTS}

The authors thank the Department of Economic Development, Jobs, Transport and Resources (Melbourne, 
Australia), the Gardiner Foundation (Melbourne, Australia), and Dairy Futures Cooperative Research Centre (Melbourne, Australia) for funding this project. Mike Coffey acknowledges financial support from the Scottish Government (Edinburgh, UK), the Department for Environment, Food and Rural Affairs (London, UK) and DairyCo (Kenilworth, UK). Provision of genotypes and phenotypes on Dutch animals by Roel Veerkamp and Yvette de Haas (Wageningen University, the Netherlands) is gratefully acknowledged. We also thank Peter Amer (AbacusBio, Dunedin, New Zealand) and Roel Veerkamp (Wageningen University, the Netherlands) for constructive comments on this manuscript. Finally, we thank Donagh Berry (Teagasc, Ireland) for useful discussions that helped to direct our thinking in devising the feed saved breeding value.

\section{REFERENCES}

Berry, D. P., M. Coffey, J. Pryce, Y. de Haas, P. Løvendahl, N. Krattenmacher, J. Crowley, Z. Wang, D. Spurlock, and K. Weigel. 2014a. International genetic evaluations for feed intake in dairy cattle through the collation of data from multiple sources. J. Dairy Sci. 97:3894-3905.

Berry, D. P., and J. Crowley. 2013. Cell Biology Symposium: Genetics of feed efficiency in dairy and beef cattle. J. Anim. Sci. 91:15941613.

Berry, D. P., E. Wall, and J. Pryce. 2014b. Genetics and genomics of reproductive performance in dairy and beef cattle. Animal 8:105121.

Calus, M. P., Y. De Haas, M. Pszczola, and R. Veerkamp. 2013. Predicted accuracy of and response to genomic selection for new traits in dairy cattle. Animal 7:183-191.

Clark, S. A., J. M. Hickey, H. D. Daetwyler, and J. H. van der Werf. 2012. The importance of information on relatives for the prediction of genomic breeding values and the implications for the makeup of reference data sets in livestock breeding schemes. Genet. Sel. Evol. 44:4.

Connor, E. E. 2015. Invited review: Improving feed efficiency in dairy production: challenges and possibilities. Animal 9:395-408.

Davis, S. R., K. Macdonald, G. Waghorn, and R. Spelman. 2014. Residual feed intake of lactating Holstein-Friesian cows predicted from high-density genotypes and phenotyping of growing heifers. J. Dairy Sci. 97:1436-1445.

de Haas, Y., M. Calus, R. Veerkamp, E. Wall, M. Coffey, H. Daetwyler, B. Hayes, and J. Pryce. 2012. Improved accuracy of genomic prediction for dry matter intake of dairy cattle from combined European and Australian data sets. J. Dairy Sci. 95:6103-6112.

DiGiacomo, K., L. Marett, W. Wales, B. Hayes, F. Dunshea, and B. Leury. 2014. Thermoregulatory differences in lactating dairy cattle classed as efficient or inefficient based on residual feed intake. Anim. Prod. Sci. 54:1877-1881.

Egger-Danner, C., J. Cole, J. Pryce, N. Gengler, B. Heringstad, A. Bradley, and K. Stock. 2015. Invited review: Overview of new traits and phenotyping strategies in dairy cattle with a focus on functional traits. Animal 9:191-207.

Erbe, M., B. J. Hayes, L. K. Matukumalli, S. Goswami, P. J. Bowman, C. M. Reich, B. A. Mason, and M. E. Goddard. 2012. Improving accuracy of genomic predictions within and between dairy cattle breeds with imputed high-density single nucleotide polymorphism panels. J. Dairy Sci. 95:4114-4129.

Gibson, J. 1986. Efficiency and performance of genetically high and low milk-producing British Friesian and Jersey cattle. Anim. Prod. 42:161-182.
Gilmour, A. R., B. J. Gogel, B. R. Cullis, and R. Thompson. 2006. ASReml User Guide Release 2.0. VSN International Ltd., Hemel Hempstead, UK.

Gonzalez-Recio, O., M. Coffey, and J. Pryce. 2014a. On the value of the phenotypes in the genomic era. J. Dairy Sci. 97:7905-7915.

Gonzalez-Recio, O., J. Pryce, M. Haile-Mariam, and B. Hayes. 2014b. Incorporating heifer feed efficiency in the Australian selection index using genomic selection. J. Dairy Sci. 97:3883-3893.

Haile-Mariam, M., O. Gonzalez-Recio, and J. Pryce. 2014. Prediction of liveweight of cows from type traits and its relationship with production and fitness traits. J. Dairy Sci. 97:3173-3189.

Herd, R. M., and P. Arthur. 2009. Physiological basis for residual feed intake. J. Anim. Sci. 87(E-Suppl.):E64-E71.

Ho, C., B. Malcolm, and P. Doyle. 2013. Potential impacts of negative associative effects between concentrate supplements, pasture and conserved forage for milk production and dairy farm profit. Anim. Prod. Sci. 53:437-452.

Macdonald, K. A., J. Pryce, R. Spelman, S. Davis, W. Wales, G. Waghorn, Y. Williams, L. Marett, and B. Hayes. 2014. HolsteinFriesian calves selected for divergence in residual feed intake during growth exhibited significant but reduced residual feed intake divergence in their first lactation. J. Dairy Sci. 97:1427-1435.

Manzanilla Pech, C. I., R. Veerkamp, M. Calus, R. Zom, A. van Knegsel, J. Pryce, and Y. De Haas. 2014. Genetic parameters across lactation for feed intake, fat-and protein-corrected milk, and liveweight in first-parity Holstein cattle. J. Dairy Sci. 97:5851-5862.

Nieuwhof, G., J. Van Arendonk, H. Vos, and S. Korver. 1992. Genetic relationships between feed intake, efficiency and production traits in growing bulls, growing heifers and lactating heifers. Livest. Prod. Sci. 32:189-202.

Prendiville, R., K. Pierce, and F. Buckley. 2009. An evaluation of production efficiencies among lactating Holstein-Friesian, Jersey, and Jersey $\times$ Holstein-Friesian cows at pasture. J. Dairy Sci. 92:6176-6185.

Pryce, J. E., J. Arias, P. J. Bowman, S. R. Davis, K. A. Macdonald, G. C. Waghorn, W. J. Wales, Y. J. Williams, R. J. Spelman, and B. J. Hayes. 2012. Accuracy of genomic predictions of residual feed intake and 250-day body weight in growing heifers using 625,000 single nucleotide polymorphism markers. J. Dairy Sci. 95:2108-2119.

Pryce, J. E, W. Wales, Y. De Haas, R. Veerkamp, and B. Hayes. 2014a. Genomic selection for feed efficiency in dairy cattle. Animal $8: 1-10$.

Pryce, J. E., O. Gonzalez-Recio, J. B. Thornhill, L. C. Marett, W. J. Wales, M. P. Coffey, Y. de Haas, R. F. Veerkamp, and B. J. Hayes. 2014b. Short communication: Validation of genomic breeding value predictions for feed intake and feed efficiency traits. J. Dairy Sci. 97:537-542.

Pszczola, M., R. Veerkamp, Y. De Haas, E. Wall, T. Strabel, and M. Calus. 2013. Effect of predictor traits on accuracy of genomic breeding values for feed intake based on a limited cow reference population. Animal 7:1759-1768.

Roche, J. R., N. C. Friggens, J. K. Kay, M. W. Fisher, K. J. Stafford, and D. P. Berry. 2009. Invited review: Body condition score and its association with dairy cow productivity, health, and welfare. J. Dairy Sci. 92:5769-5801.

Shalloo, L., J. Kennedy, M. Wallace, M. Rath, and P. Dillon. 2004. The economic impact of cow genetic potential for milk production and concentrate supplementation level on the profitability of pasture based systems under different EU milk quota scenarios. J. Agric. Sci. 142:357-369.

Strandén, I., and O. F. Christensen. 2011. Allele coding in genomic evaluation. Genet. Sel. Evol. 43:25.

Tempelman, R. J., D. Spurlock, M. Coffey, R. Veerkamp, L. Armentano, K. Weigel, Y. de Haas, C. Staples, E. Connor, and Y. Lu. 2015. Heterogeneity in genetic and nongenetic variation and energy sink relationships for residual feed intake across research stations and countries. J. Dairy Sci. 98:2013-2026.

Van Arendonk, J., G. Nieuwhof, H. Vos, and S. Korver. 1991. Genetic aspects of feed intake and efficiency in lactating dairy heifers. Livest. Prod. Sci. 29:263-275. 
VanRaden, P. M. 2004. Invited review: Selection on net merit to improve lifetime profit. J. Dairy Sci. 87:3125-3131.

VanRaden, P. M., M. E. Tooker, J. B. Cole, G. R. Wiggans, and J. H. Megonigal Jr.. 2007. Genetic evaluations for mixed-breed populations. J. Dairy Sci. 90:2434-2441.

Veerkamp, R. F. 1998. Selection for economic efficiency of dairy cattle using information on live weight and feed intake: A review. J. Dairy Sci. 81:1109-1119.

Veerkamp, R. F., M. Calus, G. de Jong, R. van der Linde, and Y. De Haas. 2014. Breeding value for dry matter intake for Dutch bulls based on DGV for DMI and BV for predictors. Proc. 10th World Congress of Genetics Applied to Livestock Production. Accessed Jul. 30, 2015. https://www.asas.org/docs/default-source/ wcgalp-proceedings-oral/115_paper_8665_manuscript_206_0. pdf?sfvrsn $=2$.

Veerkamp, R. F., G. Simm, and J. Oldham. 1994. Effects of interaction between genotype and feeding system on milk production, feed in- take, efficiency and body tissue mobilization in dairy cows. Livest. Prod. Sci. 39:229-241.

Visscher, P., P. Bowman, and M. Goddard. 1994. Breeding objectives for pasture based dairy production systems. Livest. Prod. Sci. 40:123-137.

Williams, Y. J., J. E. Pryce, C. Grainger, W. J. Wales, N. Linden, M. Porker, and B. J. Hayes. 2011. Variation in residual feed intake in Holstein-Friesian dairy heifers in southern Australia. J. Dairy Sci 94:4715-4725.

Wulfhorst, J. D, J. Ahola, S. Kane, L. Keenan, and R. Hill. 2010. Factors affecting beef cattle producer perspectives on feed efficiency. J. Anim. Sci. 88:3749-3758.

Yang, J., B. Benyamin, B. P. McEvoy, S. Gordon, A. K. Henders, D. R. Nyholt, P. A. Madden, A. C. Heath, N. G. Martin, G. W. Montgomery, M. E. Goddard, and P. M. Visscher. 2010. Common SNPs explain a large proportion of the heritability for human height. Nat. Genet. 42:565-569. 